\title{
JURISDIÇÃO CIVIL BRASILEIRA EM CRISE: DESAFIOS EM TEMPOS DE PANDEMIA $^{1}$
}

\section{BRAZILIAN CIVIL JURISDICTION IN CRISIS: CHALLENGES IN PANDEMIC TIMES}

Antônio Pereira Gaio Júnior Pós-Doutor em Direito (Universidade de Coimbra/POR). PósDoutor em Democracia e Direitos Humanos (Ius Gentium Conimbrigae/ Faculdade de Direito da Universidade de Coimbra-POR). Doutor em Direito (UGF). Mestre em Direito (UGF). Pós-Graduado em Direito Processual (UGF). Visiting Professor no Ius Gentium Conimbrigae (Faculdade de Direito da Universidade de Coimbra/POR). Professor Associado de Processo Civil e Teoria Geral do Processo da Universidade Federal Rural do Rio de Janeiro (UFRRJ). Coordenador da Pós-Graduação em Direito Processual Contemporâneo (UFRRJ). Membro da International Association of Procedural Law (IAPL). Membro do Instituto Iberoamericano de Direito Processual (IIDP). Membro do Instituto Brasileiro de Direito Processual (IBDP). Membro da International Bar Association (IBA). Membro da Associação de Direito e Economia Europeia (ADEE). Membro Efetivo da Comissão Permanente de Direito Processual Civil do IAB-Nacional. Líder do Grupo de Pesquisa "Processo Civil e Desenvolvimento" (UFRRJ/CNPq). Advogado. Rio de Janeiro/RJ. www.gaiojr.com. E-mail: jgaio@terra.com.br

RESUMO: O presente artigo procura analisar a jurisdição civil brasileira em tempos de pandemia, demonstrando a crise da mesma já em momentos anteriores, a efetiva realização

\footnotetext{
${ }^{1}$ Artigo recebido em 15/07/2020 e aprovado em 15/12/2020.
} 
da jurisdição de urgência em momento pandêmico e possíveis apontamentos para o seu exercício futuro.

PALAVRAS-ChAVE: Jurisdição Civil. Realização de Direitos. Pandemia. Crise. Futuro da Justiça.

ABSTRACT: This article seeks to analyze the Brazilian civil jurisdiction in times of pandemic, demonstrating its crisis already in previous moments, the effective realization of the emergency jurisdiction in a pandemic moment and possible notes for its future exercise.

KEY WORDS: Civil Jurisdiction. Realization of Rights. Pandemic. Crisis. Future of Justice.

\section{Jurisdição Estatal e(m) crise ${ }^{2}$}

A função judicante deve ser em qualquer Estado dito democrático, depositária da confiança do tecido social a ela submetida.

Cediço é que a aludida função exercida pelo Poder Judiciário se relaciona, inegavelmente, com o necessário compromisso de desenvolvimento nacional ${ }^{3}$ programado

\footnotetext{
${ }^{2}$ Aqui, crise deve ser entendida como "uma mudança decisiva no curso de um processo, provocando um conflito ou um profundo estado de desequilíbrio". JAPIASSÚ, Hilton; MARCONDES, Danilo. Dicionário básico de Filosofia. 3 ed. Rio de Janeiro: Jorge Zahar Editor, 1996, p.59.

${ }^{3}$ Despiciendo é dizer que o conceito de desenvolvimento, hodiernamente, se relaciona não somente com a tradicional ótica de crescimento econômico, mas, sobretudo, na perspectiva de um avanço significativo no quadro das políticas sociais voltadas à edificação da cultura de melhoria das condições daquela sociedade destinatária de tais políticas.

Ratificando tal concepção desenvolvimentista, VASCONCELOS, Marco Antonio; GARCIA, Manuel Enriquez. (Fundamentos de economia. São Paulo: Saraiva, 1998, p. 205) apontam para a ideia de que, em qualquer conceituação de desenvolvimento, há de se levar em conta e mesmo deva incluir "as alterações da composição do produto e a alocação de recursos pelos diferentes setores da economia, de forma a melhorar os indicadores de bem-estar econômico e social (pobreza, desemprego, desigualdade, condições de saúde, alimentação, educação e moradia)."

Lado outro, avançando no conceito de desenvolvimento como liberdade, numa visão do próprio desenvolvimento como um processo de expansão das liberdades reais, e ainda estas, tanto um meio de garantia quanto um fim si mesma, através da fruição de outras importantes liberdades, fundamental a obra de Amartya Sem (Development as freedom. New York: Anchor Books, 2000, p. 297).
} 
pela Carta Constitucional de 1988 (ex vi do próprio preâmbulo e inciso II do art. $3^{\circ}$, dentre outros dispositivos), traduzido em melhoria da qualidade de vida, ${ }^{4}$ bem como com a prestação jurisdicional efetiva, decorrente do próprio e prometido predicado da eficiência (art. 37, caput da CF/88).

Bem, por isso, é que necessário se faz sempre analisar a qualidade da atividade do serviço público da justiça com balizas voltadas ao seu rendimento qualitativo e quantitativo, aptos a demonstrar o estágio em amplo espectro de referenciais que também o cercam, como, por exemplo, as políticas de consenso e de conflito que marcam culturalmente o estágio de uma sociedade, as políticas públicas que bem ou mal equalizadas, acabam desaguando como forças centrípetas em judicializações sem precedentes, dentre outros tantos substratos que compõem uma análise ampla e pontencializadora de resultados.

Dito isso e sem negar que, de um modo geral, os servidores do Poder Judiciário laboram de forma séria e comprometida, fato é que o serviço público da justiça no Brasil tem vivido, há tempos, quadras extremamente difíceis.

Ainda no início do ano de 1974, ao retomar os trabalhos do Supremo Tribunal Federal-STF, o então Presidente da Corte, Eloy da Rocha, colocara em pauta para o futuro governo, o problema da premente necessidade de promover uma total reforma do Poder Judiciário, afirmando que aludido Poder parecia ser o único setor que passara quase imune pela onda da racionalização, aperfeiçoamento e modernização dos serviços públicos que, nestes 10 anos de Revolução, tem se estendido por todo o país.

E assim, concluía:

\footnotetext{
Sobre a relação intrínseca e extrínseca da função jurisdicional e do Processo em si para com o Desenvolvimento, ver GAIO JÚNIOR, Antônio Pereira. Instituições de Direito Processual Civil. 4 ed. Salvador: JusPodivm, 2020, p.37- 44.

Ainda sobre o Processo como meio de promoção do desenvolvimento como qualidade de vida, ver GRUPO DE PESQUISA PROCESSO CIVIL E DESENVOLVIMENTO (UFRRJ/CNPq). O Processo em sua perspectiva externa: meio de promoção do desenvolvimento como qualidade de vida - por uma nova fase metodológica do Processo. In: GAIO JÚNIOR, Antônio Pereira. Direito Processual em Movimento. Vol. VIII. Curitiba: CRV, 2019, p.117-154.

${ }^{4}$ Acerca do importante papel das instituições no processo de desenvolvimento, ver, dentre muitos, NÓBREGA, Maílson da. Brasil: um novo horizonte. In: ZYLBERSZTAJN, Décio; SZTAJN, Rachel.(Orgs.) Direito $e$ Economia. Análise Econômica do Direito e das Organizações. Rio de Janeiro: Elsevier, 2005, p. 291.

Mais precisamente sobre a atividade judicante do Poder Judiciário nos desígnios desenvolvimentistas do Estado Brasileiro, confira PINHEIRO, Armando Castelar. Magistrados, Judiciário e Economia no Brasil. In: ZYLBERSZTAJN, Décio; SZTAJN, Rachel.(Orgs.) Direito e Economia. Análise Econômica do Direito e das Organizações. Rio de Janeiro: Elsevier, 2005, p. 244-283; NUSDEO, Fábio. Curso de Economia: Introdução ao Direito Econômico. 5 ed.. São Paulo: RT, 2008; GAIO JÚNIOR, Antônio Pereira. Instituições de Direito Processual Civil. 4 ed. Salvador: JusPodivm, 2020.
} 
“O Judiciário, porém, permaneceu quase como estava. Sua estrutura e seu funcionamento ainda são basicamente os mesmos de quando o Brasil tinha apenas 40 ou 50 milhões de habitantes e nem sonhava com o surto de progresso que ora experimenta. O Brasil voa, enquanto o Judiciário caminha a pé." 5

Seguindo a mesma toada, em um diagnóstico para reforma do Poder Judicante elaborado pelo Supremo Tribunal Federal no ano de 1975 já indicara que a reforma da justiça brasileira, sem prejuízo do sistema peculiar à própria história do país, compreende medidas de recrutamento de juízes e sua preparação profissional, a estrutura e a competência dos órgãos judicantes, o processo e si, problemas de administração, meios materiais e pessoais de execução dos serviços auxiliares e administrativos, além de recursos em tecnologia.

Em contínua análise do estado das coisas daquela época (que não se divergem dos dias de hoje, passados 45 anos...!), afirma o relatório:

"Uma das falhas imputadas à Justiça é o do retardamento dos processos e a ineficácia na execução dos julgados. A causa é vetusta e generalizada. (...)

A pletora de processos cíveis, entre mais razões que a explicarão, encontra estímulo no desgaste do poder aquisitivo da moeda e na inexistência de atualização ou correção monetária das condenações. Obrigado, pelo Estado, a recorrer-lhe à Jurisdição, para obter reparação incompleta e desvaliosa, pela indispensável demora da demanda, com benefício do litigante sem razão." 6

Trazendo para os nossos tempos, os aludidos problemas não somente permanecem, mas se agravam, sobretudo se levarmos em conta os prognósticos da pesquisa "Justiça em Números", divulgada anualmente pelo Conselho Nacional de Justiça - CNJ. ${ }^{7}$

No âmbito do Serviço Público da Justiça brasileira, por exemplo, tivemos no ano de 2018, 78.691.031 milhões de processos em andamento. ${ }^{8}$

\footnotetext{
${ }^{5}$ SALAZAR, Alcino. Poder Judiciário. Bases para Reorganização. Forense: Rio-São Paulo, 1975, p. 14.

${ }^{6}$ SUPREMO TRIBUNAL FEDERAL. Reforma do Poder Judiciário. Diagnóstico. Brasília: Departamento de Imprensa Nacional, 1975, p.17-18.

${ }^{7}$ Principal fonte das estatísticas oficiais do Poder Judiciário, anualmente, desde 2004, o Relatório Justiça em Números divulga a realidade dos tribunais brasileiros, com muitos detalhamentos da estrutura e litigiosidade, além dos indicadores e das análises essenciais para subsidiar a Gestão Judiciária brasileira.

Disponível em: < https:/www.cnj.jus.br/wp- content/uploads/conteudo/arquivo/2019/08/justica/cont ten/ uploads/conteudo/arquivo/2019/08/justica_em_numeros20190919.pdf > . Acesso em 01.04.2020.

${ }^{8}$ É oportuno esclarecer que, conforme o glossário da Resolução CNJ 76/2009, consideram-se baixados os processos:

- Remetidos para outros órgãos judiciais competentes, desde que vinculados a tribunais diferentes;

- Remetidos para as instâncias superiores ou inferiores;
} 
No que toca à duração temporal das demandas, atendo-se aqui apenas à Justiça Estadual, pois que esta representa $80 \%$ dos processos pendentes no Poder Judiciário pátrio, no que toca ao Procedimento do Cumprimento da Sentença, a média duração de um processo gira em torno de 3 anos e 7 meses, logicamente, em sua grande maioria, antecedido por um procedimento em $1^{\circ}$ grau com duração média de 3 anos e 3 meses e de um procedimento em $2^{\circ}$ grau, este com duração média de 1 ano e 1 mês, perfazendo um total de 7 anos e 11 meses. Isso sem qualquer garantia de que, ao final, o jurisdicionado terá o seu direito restaurado com a obrigação devida efetivamente cumprida...!

Fora a questão temporal e de real efetividade na restauração do direito ora descumprido, outros pontos são nevrálgicos, tais como os gastos com o Poder Judiciário girando na faixa dos $\mathrm{R} \$ 93.7$ bilhões (aproximando de 1,4\% do PIB) quase consumido somente com folha de pessoal, o custo por habitante em $\mathrm{R} \$ 449,53$, o número ainda incipiente de magistrados (18.141 mil) correspondendo à média de 8,2 juízes para cada 100 mil habitantes9, ajudando, exponencialmente, a manter o serviço público da justiça em um quadro de difícil eficiência.

Os panoramas acima já nos dão conta de que, portanto, muito antes se sermos acometidos por uma enfermidade epidêmica amplamente disseminada (Pandemia) decorrente do Covid19,10 o momento pelo qual o Poder Judiciário pátrio já passava estava longe de ser dos melhores.

\section{Pandemia e Justiça}

Conforme referendado em linhas atrás, o momento pelo qual o serviço público da justiça brasileira passava antes mesmo do surto epidêmico que temos sentido, já se fazia consternador.

\footnotetext{
- Arquivados definitivamente;

- Em que houve decisões que transitaram em julgado e iniciou-se a liquidação, cumprimento ou execução. Portanto, exceto quanto ao arquivamento definitivo, os processos "baixados" continuam pendentes, o que deve ser levado em consideração quando estamos diante do número absoluto de processos nas esferas do Poder Judiciário.

${ }^{9}$ A média nos países europeus, p. exemplo, gira em torno de 21 magistrados por 100 mil habitantes. Disponível em : <https://www.pordata.pt/Europa/Magistrados+Judiciais+por+100+mil+habitantes-3355>. Acesso em: 08.05.2020.

${ }^{10}$ A COVID-19 é uma doença causada pelo coronavírus SARS-CoV-2, que apresenta um quadro clínico que varia de infecções assintomáticas a quadros respiratórios graves. Disponível em: < https://coronavirus. saude.gov.br/sobre-a-doenca\#o-que-e-covid>. Acesso em: 10.05.2020.
} 
Outrossim, alardeados fomos todos, em escala mundial, pela Covid19, doença que fora identificada pela primeira vez em Wuhan, na província de Hubei, República Popular da China, em 1 de dezembro de 2019, tendo o primeiro caso reportado em 31 de dezembro do mesmo ano. ${ }^{11}$

Em 11 de março de 2020, a Organização Mundial da Saúde declarou o surto uma pandemia, tendo até 10 de maio de 2020, pelo menos 402514 casos da doença confirmados em mais de 187 países e territórios. ${ }^{12}$

No Brasil, em 25 de fevereiro, a Secretaria Estadual da Saúde de São Paulo confirmou o primeiro caso, tratando-se de um paciente de 61 anos que esteve em viagem pela Itália entre os dias 9 a 21 de fevereiro. ${ }^{13}$ Mesmo antes da confirmação do caso, o Brasil já havia elevado seu alerta para a doença de nível 2 (perigo iminente) para 3, no qual se declara emergência de saúde pública de importância nacional. A 5 de março, o Ministério da Saúde confirmou que o Brasil havia registrado a transmissão local do vírus em São Paulo. ${ }^{14}$

Mais adiante, no dia 17 de março, registrou-se a primeira morte no Brasil pelo novo coronavírus, de um homem de 62 anos, este que estava internado em um hospital na cidade de São Paulo. ${ }^{15}$ No mesmo dia, uma mulher morreu no Rio de Janeiro, após contrair o vírus da sua patroa no Leblon. ${ }^{16}$

Uma vez deixando de ser possível conter a propagação da doença, as medidas passam a estar focadas em atrasar e mitigar os seus efeitos na sociedade e no sistema de saúde, ${ }^{17}$

11 Disponível em:< https://www.who.int/emergencies/diseases/novel-coronavirus-2019 >. Acesso em: 10.05.2020.

12 Disponível em: < https://www.arcgis.com/apps/opsdashboard/index.html\#/bda7594740fd4029942346 7b48e9ecf6>. Acesso em: 10.05.2020.

13 Disponível em: < https://g1.globo.com/sp/sao-paulo/noticia/2020/02/25/ministerio-da-saude-investigapossivel-paciente-com-coronavirus-em-sp-caso-foi-para-contraprova.ghtml > . Acesso em 10.05.2020.

${ }^{14}$ Disponível em: < https://www.saude.gov.br/noticias/agencia-saude/46493-coronavirus-com-8-casos-co nfirmados-brasil-monitora-636-suspeitos>. Acesso em: 20.05.2020.

${ }^{15}$ Disponível em:< https://g1.globo.com/sp/sao-paulo/noticia/2020/03/17/estado-de-sp-tem-o-primeiro-ca so-de-morte-provocada-pelo-coronavirus.ghtml>. Acesso em:11.05.2020.

${ }^{16}$ Disponível em:< https://noticias.uol.com.br/saude/ultimas-noticias/redacao/2020/03/19/primeira-vitima -do-rj-era-domestica-e-pegou-coronavirus-da-patroa.htm>. Acesso em:11.05.2020.

${ }^{17}$ No momento em que escrevemos estas letras, se confirmam no Brasil 158 mil infectados, 64.867 mortos, 1.603.055 confirmados e 978.615recuperados, isso em dados oficiais, visto que se projetam números maiores no país, haja vista o não acesso a todos que se adoecem/falecem, aos exames necessários para a apuração de infecção ou não pelo Covid19. <https://www.google.com/search?q=covid+brasuil\&oq=covid+brasuil\&aqs=chrome..69i57j017.5159j0j4\&so urceid $=$ chrome $\&$ ie $=U$ UTF-8 $>$. Acesso em: 05.07.2020. 
sendo fundamental o papel dos Poderes Públicos na gestão do surto, esta que consiste em tentar diminuir o pico epidemiológico, um processo denominado "achatamento a curva epidemiológica".

Pois bem. No contexto do Poder Judiciário, por meio do Conselho Nacional de Justiça-CNJ editada fora a Resolução n.313, de 19.03.2020, esta objetivando estabelecer, no âmbito do Poder Judiciário, um regime de Plantão Extraordinário, para fins de uniformizar o funcionamento dos serviços judiciários, no intuito de prevenir o contágio pelo novo Coronavírus - Covid-19, e com isso, garantir o acesso à justiça em período emergencial.

Neste sentido, os prazos para a práticas de atos processuais que até então estavam correndo plenamente, pela Resolução em tela, foram suspensos (art. $5^{\circ}$ ), exceto a prática de atos processuais necessários à preservação de direitos e de natureza urgente, sempre respeitado o disposto no artigo $4^{\circ}$ da Resolução, tratando-se aí do que denominamos “Jurisdição de Urgência”, quando então o próprio texto normativo aponta para quais matérias teriam a prioridade de serem recebidas e concedidas as prestações jurisdicionais devidas, tudo levando-se em consideração o seu próprio caráter extraordinário e de urgência.

Estabeleceu o art. $4^{\circ}$ da Resolução em comento:

"Art. $4^{\circ}$ No período de Plantão Extraordinário, fica garantida a apreciação das seguintes matérias: I - habeas corpus e mandado de segurança; II - medidas liminares e de antecipação de tutela de qualquer natureza, inclusive no âmbito dos juizados especiais; III comunicações de prisão em flagrante, pedidos de concessão de liberdade provisória, imposição e substituição de medidas cautelares diversas da prisão, e desinternação; IV - representação da autoridade policial ou do Ministério Público visando à decretação de prisão preventiva ou temporária; $\mathrm{V}$ - pedidos de busca e apreensão de pessoas, bens ou valores, interceptações telefônicas e telemáticas, desde que objetivamente comprovada a urgência; VI - pedidos de alvarás, pedidos de levantamento de importância em dinheiro ou valores, substituição de garantias e liberação de bens apreendidos, pagamento de precatórios, Requisições de Pequeno Valor - RPVs e expedição de guias de depósito; VII - pedidos de acolhimento familiar e institucional, bem como de desacolhimento; VIII pedidos de progressão e regressão cautelar de regime prisional, concessão de livramento condicional, indulto e comutação de penas e pedidos relacionados com as medidas previstas na Recomendação CNJ no 62/2020; IX - pedidos de cremação de cadáver, exumação e inumação; e X - autorização de viagem de crianças e adolescentes, observado o disposto na Resolução CNJ no 295/2019." 
Lado outro, algumas atividades permaneceram, na medida do possível, em funcionamento, pois estabeleceu a Resolução sua garantia mínima, pois essencial, como estabeleceu o $\S 1^{\circ}$ do art. $2^{\circ}$, tais como a distribuição de processos judiciais e administrativos, com prioridade aos procedimentos de urgência; a manutenção de serviços destinados à expedição e publicação de atos judiciais e administrativos; o atendimento aos advogados, procuradores, defensores públicos, membros do Ministério Público e da polícia judiciária, de forma prioritariamente remota e, excepcionalmente, de forma presencial; a manutenção dos serviços de pagamento, segurança institucional, comunicação, tecnologia da informação e saúde; e ainda as atividades jurisdicionais de urgência já comentadas alhures.

Destaca-se que o trabalho via remoto, objetivando impedir o contato pessoal entre os atores do processo e mesmo entre servidores do serviço público da justiça, foram objeto de regulação pela Resolução n.313, nos termos em que ficara suspenso o atendimento presencial de partes, advogados e interessados, sendo, então, realizado remotamente pelos meios tecnológicos disponíveis e à responsabilidade de cada unidade judiciária, esta que deveria manter canal de atendimento remoto, a ser amplamente divulgado pelos respectivos tribunais. Uma vez não logrado atendimento na forma supracitada, os tribunais deveriam providenciar meios para atender, presencialmente, Advogados, públicos e privados, membros do Ministério Público e Polícia Judiciária, durante o expediente forense, ex vi do art. $3^{\circ}, \S \S 1^{\circ}$ e $2^{\circ}$.

\section{Práticas Jurisdicionais em tempos de Pandemia (Jurisdição de Urgência)}

Como ora observado, a Resolução n.313 do CNJ, em seu art. $4^{\circ}$, apresentou a tipicidade de demandas e matérias aptas ao conhecimento do Poder Judiciário em tempos de pandemia, o que inaugurou neste tempo a jurisdição de urgência, dada a própria características dos assuntos autorizados ao conhecimento do órgão judicial, ainda que variável em sua natureza material.

Nisso, conteúdos relativos, por exemplo, ao habeas corpus e mandado de segurança; medidas liminares e de antecipação de tutela de qualquer natureza, inclusive no âmbito dos juizados especiais, dentre outros, permitiram ser apreciados, dada as questões urgentes - mas também provisórias - decorrentes da sua própria gênese. 
Em sede das Cortes Superiores, já fora possível observar neste tempo a atuação do Supremo Tribunal Federal, de forma colegiada ou monocrática, em importantíssimos e sensíveis temas para a realidade pátria, tais como:

(i) a possibilidade de adoção por parte de estados e municípios, no âmbito de suas competências e em seu território, respectivamente, medidas de restrição à locomoção intermunicipal e local durante o estado de emergência decorrente da pandemia do novo coronavírus, sem a necessidade de autorização do Ministério da Saúde para a decretação de isolamento, quarentena e outras providências. ${ }^{18}$

(ii) A suspensão da eficácia de dois dispositivos da Medida Provisória (MP) n. 927/2020, que autorizou empregadores a adotarem medidas excepcionais em razão do estado de calamidade pública decorrente da pandemia do novo coronavírus. ${ }^{19}$

(iii) O deferimento de medida cautelar para afastar a exigência de demonstração de adequação orçamentária em relação à criação e expansão de programas públicos destinados ao enfrentamento da pandemia, tudo a partir de pleito da Advocacia Geral da União-AGU para afastamento de algumas exigências da Lei de Responsabilidade Fiscal (Lei Complementar n.101/2000) e da Lei de Diretrizes Orçamentárias (Lei n. 13.898/2020) relativas, conforme dito, a programas de combate ao Covid19 e de proteção da população vulnerável à pandemia. ${ }^{20}$

(iv) O não cabimento da Reclamação (Rcl) 39884, ajuizada pela Igreja Evangélica Assembleia de Deus contra decisão judicial que validou norma do Estado do Mato Grosso, vedando a realização de cultos, missas e celebrações religiosas durante a pandemia do coronavírus.

(v) A inconstitucionalidade de dispositivos relativos às normas do Ministério da Saúde e da Agência Nacional de Vigilância Sanitária (Anvisa) que excluíam do rol de habilitados para doação de sangue os "homens que tiveram relações sexuais com outros homens e/ou as parceiras sexuais destes nos 12 meses antecedentes", dentre outros.

\footnotetext{
18 ADPF n.672.

${ }^{19}$ As ações foram ajuizadas pelo Partido Democrático Trabalhista (ADI n.6342), pela Rede Sustentabilidade (ADI n.6344), pela Confederação Nacional dos Trabalhadores Metalúrgicos (ADI n.6346), pelo Partido Socialista Brasileiro (ADI n.6348), pelo Partido Comunista do Brasil (PCdoB), pelo Partido Socialismo e Liberdade (PSOL) e pelo Partido dos Trabalhadores (PT) conjuntamente (ADI n.6349), pelo partido Solidariedade (ADI n.6352) e pela Confederação Nacional dos Trabalhadores da Indústria (ADI n.6354).

${ }^{20}$ ADI n. 6341.
} 
Nota-se que, a despeito de estarmos em momento de extremo abalo social, econômico, político, econômico e mesmo político, as matérias enfrentadas pela Corte Superior não deixam dúvidas de sua importância para a segurança jurídica que exige a ocasião, mesmo porque todas umbilicalmente ligadas ao surto vivenciado.

No âmbito do Superior Tribunal de Justiça-STJ não fora diferente.

Foram enfrentadas até então matérias de extrema importância, inclusive para a ocasião, dentre elas:

(i)A extinção de mandado de segurança no qual a família de um paciente internado no Rio de Janeiro, com quadro condizente com infecção pelo novo coronavírus (Covid-19), buscava ter direito a tratamento imediato com o uso de cloroquina ou hidroxicloroquina. $\mathrm{O}$ mandado de segurança foi impetrado contra o Ministro da Saúde.

Além de não se indicar qual ato de efeitos concretos por parte do Ministro da Saúde teria violado direito líquido e certo do paciente, a Ministra Relatora, Assusete Magalhães, observou que, no caso, sequer houve laudo ou atestado médico recomendando o uso da medicação postulada ao impetrante, como também não consta dos autos nenhuma comprovação de que a médica que o acompanha teria deixado de usar o medicamento por determinação direta do Ministro da Saúde. ${ }^{21}$

(ii) $\mathrm{O}$ indeferimento do habeas corpus coletivo no qual a Defensoria Pública do Amazonas pedia a concessão de prisão domiciliar para todos os presos do regime fechado do Complexo Penitenciário Anísio Jobim, em Manaus, que fossem integrantes do grupo de risco da pandemia do novo coronavírus (Covid-19).

Em sua decisão - que seguiu a linha de entendimento adotada pelo STJ em processos como os Habeas Corpus 567.779, 571.796 e 570.440 e pelo Supremo Tribunal Federal (STF) na Ação Penal 996 -, o Ministro Rogério Schietti Cruz afirmou que não é possível à corte superior analisar de forma genérica o pedido de substituição das prisões, sem verificação das circunstâncias individualizadas de cada preso - competência que cabe, como regra, ao juiz de execuções criminais, que melhor conhece a realidade local. ${ }^{22}$

\footnotetext{
${ }^{21}$ Disponível em: < http://www.stj.jus.br/sites/portalp/Paginas/Comunicacao/Noticias/Ministra-extingue-p rocesso-de-paciente-com-suspeita-de-coronavirus-que-exigia-tratamento-com-cloroquina.aspx $>$. Acesso em: 11.05.2020.

${ }^{22}$ Disponível em: < http://www.stj.jus.br/sites/portalp/Paginas/Comunicacao/Noticias/Pandemia-nao-dispe nsa-analise-da-situacao-individual--diz-ministro-ao-negar-prisao-domiciliar-coletiva-no-AM.aspx>. Acesso em: 11.05.2020.
} 
(iii) Acolhimento de Tutela Provisória pelo ministro Napoleão Nunes Maia Filho em pleito de uma empresa de manutenção de elevadores para a liberação de cerca de R \$ 80 mil que estavam bloqueados em uma execução fiscal.

Apesar de ter havido parcelamento da dívida tributária, discute-se no processo a possibilidade de redirecionamento dos valores para o pagamento de outros débitos.

No pedido de urgência, a empresa alegou que está fechada durante a pandemia decorrente do Covid-19 e, em consequência, teria dificuldade para arcar com a folha de pagamentos; por isso, o ministro supracitado determinou que os valores desbloqueados fossem utilizados exclusivamente na quitação de salários e encargos.

Durante a execução proposta pela Fazenda Pública, a empresa requereu a liberação dos valores que haviam sido penhorados pelo sistema Bacenjud, sob o argumento de que o débito foi incluído em programa de parcelamento. Entretanto a União se opôs ao desbloqueio, porque existiriam outras ações executivas em tramitação na Justiça Federal, motivo pelo qual pediu a transferência dos valores para outros processos. ${ }^{23}$

(iv) deferimento de pedido de liminar para que um bebê de oito meses de idade fosse retirado do abrigo e devolvido a um casal que busca regularizar a sua adoção, tudo em razão dos perigos decorrentes da epidemia do novo coronavírus (Covid-19) e como forma de proteger o melhor interesse da criança, de acordo com o ministro do Villas Bôas Cueva.

Além de levar em consideração informações de que o bebê tem problemas respiratórios - e que, portanto, poderia estar mais suscetível ao risco epidemiológico da Covid-19 - o referido ministro entendeu que o acolhimento institucional não poderia se sobrepor à manutenção da criança no núcleo familiar que a recebeu desde o seu nascimento, sobretudo por inexistir evidência de conduta prejudicial por parte do casal. ${ }^{24}$

(v) Determinação de que durante a pandemia do novo coronavírus (Covid-19), a Unimed de São José do Rio Preto (SP) mantenha o plano de saúde de um casal de idosos até

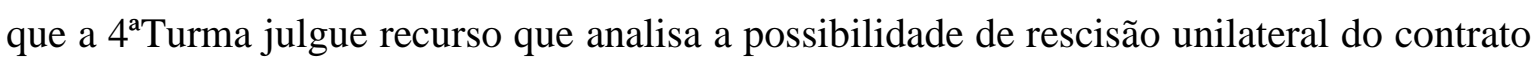
por parte da administradora. O plano seria encerrado em 30 de março.

\footnotetext{
${ }^{23}$ Disponível em: < ttp://www.stj.jus.br/sites/portalp/Paginas/Comunicacao/Noticias/Ministro-libera-valor es-de-penhora-fiscal-para-que-empresa-pague-salarios-durante-pandemia.aspx>. Acesso em: 11.05.2020.

${ }^{24}$ Disponível em: < http://www.stj.jus.br/sites/portalp/Paginas/Comunicacao/Noticias/Em-meio-a-pandem ia--ministro-determina-que-bebe-saia-de-abrigo-e-fique-com-casal-interessado-na-adocao.aspx > . Acesso cesso em: 12.05.2020.
} 
Trata-se de casal que mantinha o plano de saúde coletivo há mais de 25 anos, quando recebeu a comunicação da Unimed de que o contrato seria rescindido. Na Justiça, eles alegaram ter direito à permanência definitiva no plano, mediante o pagamento regular das mensalidades, mas a Unimed afirmou que o contrato coletivo admite a rescisão unilateral e que os beneficiários poderiam fazer a migração para um plano de saúde individual ou familiar. $^{25}$

Ao mesmo tempo em que se presencia uma diversidade de conteúdos dos mais sensíveis em sede de jurisdição de urgência conforme acima exposto, um imenso volume de demandas por todo o pais se presenciar, ${ }^{26}$ isso desde as Cortes Superiores passando pelos Tribunais, Seções Judiciárias e Comarcas de todo o país, obrigando o próprio Poder Judiciário brasileiro a tomar uma série de medidas de contenção ou de isolamento social frente à pandemia, a fim de se evitar o contato físico entre os atores processuais, servidores e jurisdicionados de um modo geral.

Nestes termos, trabalhos remotos e audiências virtuais foram implementadas como antídotos para o momento extraordinário presenciado, tentando, na medida do possível, estabelecer parâmetros para que se desse continuidade regular ao serviço público da justiça.

Nas cortes superiores, o Supremo Tribunal Federal, por exemplo, editou a Resolução n.670, de 23.03.2020 estabelecendo novas medidas temporárias de prevenção ao contágio pelo Novo Coronavírus (COVID-19), destacando, dentre outros pontos, suspensão dos prazos processuais de processos físicos, a contar da sua publicação e até o dia 30 de abril de 2020, mas possibilitando a prática de atos urgentes, em conformidade com o que estabelece o art.4 a da Resolução n.313, de 19.03.2020, do Conselho Nacional de Justiça , a suspensão de todo atendimento presencial aos públicos externo e interno, salvo as exceções contidas na própria Resolução, tendo art. $3^{\circ}$ desta estabelecido que o "atendimento judicial de partes, advogados, procuradores, defensores e interessados se dará por meio telefônico ou eletrônico, mantido o atendimento presencial ao público, inclusive o protocolo físico de petições, no horário de $13 \mathrm{~h}$ às $17 \mathrm{~h}$, exclusivamente para processos físicos urgentes"; realização de trabalho remoto para todas as atividades compatíveis, independentemente de

\footnotetext{
${ }^{25}$ REsp n. 1840428.

${ }^{26}$ Importantes dados sobre os trabalhos da magistratura brasileira em tempos de pandemia pode ser encontrado em https://www.amb.com.br/coronavirus-confira-decisoes-do-judiciario-relacionadas-ao-enfrentamento-dapandemia/?doing_wp_cron=1589496577.2177391052246093750000.
} 
aprovação prévia; suspensão de todos os serviços internos não essenciais incompatíveis com o trabalho remoto; redução ao nível mínimo necessário para a manutenção dos serviços internos essenciais incompatíveis com o trabalho remoto, dentre outros conteúdos.

Já, para fins de julgamento por meio eletrônico e a realização de sustentação oral em ambiente virtual, fora editada Emenda Regimental n. 53 de 18.03.2020, estabelecendo o que art. 21-B do seu Regimento Interno passa a vigorar com as seguintes alterações:

"Art. 21-B Todos os processos de competência do Tribunal poderão, a critério do relator ou do ministro vistor com a concordância do relator, ser submetidos a julgamento em listas de processos em ambiente presencial ou eletrônico, observadas as respectivas competências das Turmas ou do Plenário.

$\S 1^{\circ}$ Serão julgados preferencialmente em ambiente eletrônico os seguintes processos: I - agravos internos, agravos regimentais e embargos de declaração; II - medidas cautelares em ações de controle concentrado; III - referendo de medidas cautelares e de tutelas provisórias; IV - demais classes processuais, inclusive recursos com repercussão geral reconhecida, cuja matéria discutida tenha jurisprudência dominante no âmbito do STF.

$\S 2^{\circ}$ Nas hipóteses de cabimento de sustentação oral previstas neste regimento interno, fica facultado à Procuradoria-Geral da República, à Advocacia-Geral da União, à Defensoria Pública da União, aos advogados e demais habilitados nos autos encaminhar as respectivas sustentações por meio eletrônico após a publicação da pauta e até 48 horas antes de iniciado o julgamento em ambiente virtual."

Ainda que a prática de julgamentos virtuais já tenha sido implementada há anos no STF - fora introduzida pela Emenda Regimental n.27, de 30.04.2007, para decisão, pelo plenário, sobre questões acerca da existência ou não de Repercussão Geral em sede de Recursos Extraordinários - fato é que as possibilidades de julgamento por esta via, como se vê, ampliou consideravelmente conforme se vê na Emenda Regimental supra mencionada e a critério do relator ou do ministro vistor com a concordância do relator, ainda que a lista preferencial seja elencada no $\S 1^{\circ}$ da digitada Emenda, o que não há de olvidar críticas ao destacado "critério" do relator, este que sequer teria o dever de indicar os parâmetros determinantes para tal escolha de julgamento, o que, pensamos, em sendo decisão que reflete no interesse das próprias partes e da jurisdição, deve ter a devida motivação e fundamentação explicitada.

Deveras destacar que alteração significativa se deu com a Resolução n. 672, onde em seu art. $1^{\circ}$ estabelece que as sessões de julgamento do Plenário e das Turmas, a critério da 
respectiva Presidência, poderão ser realizadas inteiramente por videoconferência, garantindo o seu acompanhamento na íntegra, realizando-se a sustentação oral também por tal meio, desde que se faça a inscrição mediante formulário eletrônico disponibilizado no sítio eletrônico do STF até 24 horas antes da sessão (alteração promovida pela Resolução n. 676) e se utilize da mesma ferramenta a ser adotada pelo Tribunal.

Talvez com as sessões por videoconferência, tende-se a aproximar mais dos julgamentos presenciais, ainda com todos os seus limites, estes que vão desde a própria instabilidade que a rede mundial de computadores oferece nos mais diversos locais deste país de dimensões continentais até a presença física frente aos julgadores, o que é sempre importante para eventuais esclarecimentos no feito, ainda que também seja possível fazê-lo por videoconferência.

Destarte, há de assinalar que, a partir do 15.05 , se dará a primeira sessão plenária do STF realizada por videoconferência, cuja inovação tem como objetivo reforçar as medidas adotadas pelo Tribunal para reduzir a circulação interna de pessoas e o deslocamento dos trabalhadores como forma de combater a pandemia. ${ }^{27}$

Notadamente, os demais tribunais do país seguem a mesma cartilha dos julgamentos virtuais ou por videoconferência, com as sustentações orais, seja nos moldes do envio na forma escrita ou ainda por meio de videoconferência, sendo que o CNJ disponibilizou em sítio eletrônico no período de isolamento social decorrente da pandemia de Coronavírus (COVID-19), a utilização da Plataforma Emergencial de Videoconferência para Atos Processuais - Cisco Webex.

Mas em tempos de pandemia, duas questões nos chamam a atenção.

A primeira decorrente da Portaria n. 6.414/CGJ/2020 do Tribunal de Justiça de Minas Gerais-TJMG, que disciplina o procedimento experimental de realização de audiências por videoconferência nas unidades judiciárias da Justiça de Primeira Instância do Estado de Minas Gerais, no período de isolamento social decorrente da pandemia de Coronavírus (COVID-19).

Uma vez designando respectiva audiência, o juiz de direito determinará a intimação do Ministério Público e das partes, por seus advogados, para, no prazo de 48 horas,

\footnotetext{
${ }^{27}$ As sessões terão transmissão pela TV Justiça, Rádio Justiça e pelo canal do STF no YouTube. Disponível em: <http://portal.stf.jus.br/noticias/verNoticiaDetalhe.asp?idConteudo=440825\&ori=1>. Acesso em 15.05.2020.
} 
manifestarem concordância quanto à realização da audiência por videoconferência ou à impossibilidade de participação, hipótese em que o juiz de direito decidirá sobre o adiamento do ato, ex vi do art. $3^{\circ}$ caput.

Manifestando-se concordes com a mesma será disponibilizado ao juiz de direito, aos advogados e representante do Ministério Público e da Defensoria Pública e aos demais participantes o link para acesso à videoconferência, por meio da internet (art. $4^{\circ}$ )

Não obstante isso

\begin{abstract}
"as partes e as testemunhas deverão comparecer à sede predial da unidade judiciária, devidamente munidas de documento oficial de identificação original, com foto, e dos equipamentos de proteção individual, inclusive máscara, em virtude da pandemia de COVID19, para participação da audiência por videoconferência no local, exclusivamente na presença de servidor designado para o ato, sob a presidência do juiz competente, que de tudo participará também por videoconferência" $\left(\S 1^{\circ}\right.$ do art. $\left.4^{\circ}\right)$.
\end{abstract}

Ora, se a audiência por videoconferência se faz, exatamente, para fins de total proteção ao isolamento social e higidez na saúde de todos, expor partes e testemunhas a deslocamento à sede do juízo para tal, sendo que a elas sequer se deu direito à manifestação de aceite, não faz qualquer sentido!

$\mathrm{O} \S 2^{\circ}$ do art. $4^{\circ}$ ainda faz a seguinte ressalva:

"Não será permitida a realização de ato presencial, salvo em relação às partes e testemunhas, para colheita de suas declarações ou depoimentos por videoconferência."

E diga-se ainda, não está a se referir a qualquer réu preso, pois, neste caso, sua participação será garantida também por meio de videoconferência, a partir de link para acesso a ser enviado ao diretor do estabelecimento prisional, quando possível ( $\left(3^{\circ}\right.$ do art. $4^{\circ}$ )

Há de se entender que os limites ao bom senso são inerentes ao próprio direito que se quer descobrir com a colaboração daqueles interessados ou não no deslinde da demanda em questão, para não citar o servidor que ali prestará assistência às aludidas partes e testemunhas que, por ventura, se aventurem a tal deslocamento.

Já a segunda advém das modificações operadas pela Lei n. 13.994, de 24.04.2020 à Lei n. 9.099, de 26.09.1995 (lei que dispõe sobre os Juizados Especiais Cíveis e Criminais).

No que nos interessa o comentário, a modificadora lei introduz as seguintes disposições ao conjunto normativo dos Juizados Especiais: 
“ $\S 2^{\circ}$ É cabível a conciliação não presencial conduzida pelo Juizado mediante o emprego dos recursos tecnológicos disponíveis de transmissão de sons e imagens em tempo real, devendo o resultado da tentativa de conciliação ser reduzido a escrito com os anexos pertinentes.

Art. 23. Se o demandado não comparecer ou recusar-se a participar da tentativa de conciliação não presencial, o Juiz togado proferirá sentença."

Observa-se, com a maior clareza, a positiva e bem-vinda abertura para a possibilidade de conciliação não presencial no âmbito dos Juizados Especiais - aí tanto estaduais, federais e da fazenda pública ${ }^{28}$ - mediante o emprego dos recursos tecnológicos disponíveis de transmissão de sons e imagens em tempo real, sendo reduzido a escrito com os anexos pertinentes, podendo, inclusive, uma vez obtida a conciliação e homologada pelo juiz togado, formar o respectivo título executivo judicial ( $\$ 1^{\circ}$ do art. 22 da Lei 9.099/95, diga-se, igualmente alterado pela lei em comento).

O que nos causa espécie, configurando-se em um completo, desarrazoado e desequilibrado ônus à parte ré é o que se estampa no art.23 supra, estabelecendo que a recusa em participar da tentativa de conciliação não presencial, autorizará o órgão julgador a proferir a respectiva sentença, sugerindo aí, então, uma espécie de efeito da revelia em sentido estrito aplicada ao réu, correspondendo como incontroversos os fatos narrados pelo autor e que dão suporte à sua pretensão apresentada na demanda. ${ }^{29}$

Parece-nos que passa ao largo do legislador a incipiência quanto ao acesso a meios tecnológicos pela população brasileira. ${ }^{30}$

Outrossim, a imaginar para além da pandemia, penso que será necessário para a validade da sentença prolatada nos casos de ausência da parte ré, como dispõe a lei em comento, que, no mínimo, esta aceite a forma de audiência por videoconferência; no entanto, no dia se nega a conectar-se por tal via, assim mesmo mediante comprovação da referida

\footnotetext{
${ }^{28}$ Sobre a aplicação subsidiária da Lei n.9.0990/95 ás Leis n. 10.259/01 e 12.153/09, cf. o nosso O Processo nos Juizados Especiais Cíveis Estaduais, Federais e da Fazenda Pública. 3 ed. Belo Horizonte: Del Rey, 2019. ${ }^{29}$ GAIO JÚNIOR, Antônio Pereira. Instituições de Direito Processual Civil. 4 ed. Salvador: JusPodivm, 2020, p.443.

${ }^{30}$ Um em cada 4 brasileiros não tem acesso à internet. Número representa 46 milhões excluídos do acesso à informação.

Disponível em: < https://agenciabrasil.ebc.com.br/economia/noticia/2020-04/um-em-cada-quatro-brasile ileiros-nao-tem-acesso-internet. Acesso em: 16.05.2020.
} 
negativa, pois poderá em muitos casos a parte em questão ser surpreendida com péssima conexão de dados ou mesmo a sua completa ausência.

\section{4. À Guisa Final. Futuros da Justiça ${ }^{31}$}

Longe de se fazer qualquer prognóstico para além do tempo de passagem da pandemia que nos assola e que se encontra no mundo da incerteza quanto à descoberta de antídotos para inaugurar seu final, ${ }^{32}$ os caminhos até então não inspiram qualquer possibilidade de melhora acentuada na prestação jurisdicional.

Não se nega que a justiça brasileira esteja alcançando elevados índices de produtividade neste tempo, mas, em igual proporção, é crível a espera de um volume de demandas que assolarão o Poder Judicante durante e pós pandemia, seja na seara trabalhista, decorrente das relações laborais que tiveram impactos fortes decorrentes do binômio capitaltrabalho, extremamente debilitado com a recessão econômica por que passa a sociedade brasileira, como na área consumerista, proveniente de quebras unilaterais de contratos ou ainda impulsionadas pela má prestação de serviços públicos, dentre outras variedades fáticas.

É fato que o serviço público da justiça tem se aproximado há tempos de recursos tecnológicos, mirando avanços na prestação jurisdicional por meio da substituição do produto físico (no caso, papel e tinta — composto de átomos) pelo digital (composto de bits), com a adoção do processo eletrônico, notadamente, um caminho sem volta, desmaterializando quase a totalidade o seu acervo de processos, onde cerca de 79,2\% estão em curso pela via digital, ainda que, registra-se, não impactando substancialmente na duração razoável do lapso temporal das demandas em si.

Com a pandemia acelera-se com mais velocidade o uso da citada via digital, tendo o Conselho Nacional de Justiça, como demonstrado em linhas anteriores, editado atos normativos para a execução de suas atividades em ambiente virtual, assim como o Supremo

\footnotetext{
${ }^{31}$ Sobre os novos paradigmas da jurisdição brasileira, confira, dentre outros, GAIO JÚNIOR, Antônio Pereira. Jurisdição Civil: reflexões sobre os novos paradigmas para a sua compreensão. In: GAIO JÚNIOR, Antônio Pereira; PINHO, Humberto Dalla Bernardina (Coords.). Teoria Geral do Processo Civil. Novos Paradigmas frente ao CPC/2015. Rio de Janeiro: GZ, 2018, p.1-32; GRINOVER, Ada Pellegrini. Ensaio sobre a processualidade. Brasília: Gazeta Jurídica, 2016.

${ }^{32}$ Cientistas afirmam que desenvolver vacina para covid-19 em dois anos seria um recorde. Disponível em: $<$ https://exame.abril.com.br/ciencia/desenvolver-vacina-para-covid-19-em-dois-anos-seria-um-recorde-di zkalil/>. Acesso em: 16.05.2020.
} 
Tribunal Federal e o Superior Tribunal de Justiça, o que também fora acompanhado pelas inúmeras unidades judiciárias brasileiras.

São adaptações que, a despeito de já estarem em curso mesmo antes da crise pandêmica, receberam com o advento desta uma carga de necessidades urgentes de implantações, a fim de levarem a cabo de forma eficiente a prestação do serviço da justiça, dado o necessário distanciamento social implementado na federação de um modo geral, tendo a implantação do uso da inteligência artificial, de forma gradativa, seguindo o mesmo desiderato.

Nisso, no entanto, deve ser considerado na razão de Yuval Harari, para quem

"decisions that in normal times could take years of deliberation are passed in a matter of hours. Immature and even dangerous technologies are pressed into service, because the risks of doing nothing are bigger." 33

Lado outro, parece-nos ser verdade também que o acesso a instrumentos de solução de contendas pela via online em maior volume e variedade a cada dia, apresenta-se como um caminho importante e uma alternativa para um possível seguimento de resolução mais presta de conflitos, favorecendo o esforço para uma política de consenso, ao contrário da refratária política do conflito que, historicamente, experimentamos. ${ }^{34}$

A denominada Online Dispute Resolution - ODR, já é uma realidade em vários países $^{35}$ e em uma variedade de matérias, consistindo na utilização dos recursos da tecnologia para a resolução propícia (ou alternativa) de litígios.

Se estamos a falar do futuro da solução de disputas e dos limites que os efeitos póspandemia podem alcançar, notadamente, os contatos físicos em menor potencial já se colocam como algo palpável, sobretudo quando o consumo eletrônico por meio de compras na rede mundial de computadores bate recordes nestes tempos de isolamento social, tendo o e-commerce crescido $81 \%$ nestes tempos, sendo impulsionado por alimentos e bebidas

33 Disponível em: <https://www.ft.com/content/19d90308-6858-11ea-a3c9-1fe6fedcca75> . Acesso em 25.06.2020.

${ }^{34}$ É de se perceber que após o advento do Código de Processo Civil brasileiro de 2015, com o estabelecimento de audiências de conciliação e mediação antes mesmo da apresentação da peça contestatória por parte do réu (casos de direitos transacionáveis), os índices conciliatórios endoprocessuais continuam em níveis muito abaixo do esperado, onde para cada 100 processos, apenas 12 terminam de forma conciliatória.

Disponível em: <https://www.cnj.jus.br/wp- content/uploads/conteudo/arquivo/2019/08/justica_em_nu meros20190919.pdf > . Acesso em:25.06.2020.

${ }^{35}$ Cf. GAIO JÚNIOR, Antônio Pereira. Consumidor e a Solução de Conflitos no âmbito da União Europeia. Porto: Juruá Editorial, 2020. 
(aumento de 294,8\% em relação a abril de 2019), instrumentos musicais (+252,4\%), brinquedos $(+241,6 \%)$, eletrônicos $(+169,5 \%)$ e cama, mesa e banho $(+165,9 \%) .{ }^{36}$

Bem por isso, mais do que natural a possibilidade de também tentar a solução de controvérsias pelos próprios canais virtuais ou em linha. ${ }^{37}$

Para além de outros prognósticos que, de certo, hão de serem construídos, estas linhas já nos parecem suficientes.

\section{REFERÊNCIAS}

GAIO JÚNIOR, Antônio Pereira. Instituições de Direito Processual Civil. 4 ed. Salvador: JusPodivm, 2020.

GAIO JÚNIOR, Antônio Pereira. Consumidor e a Solução de Conflitos no âmbito da União Europeia. Porto: Juruá Editorial, 2020.

GAIO JÚNIOR, Antônio Pereira. O Processo nos Juizados Especiais Cíveis Estaduais, Federais e da Fazenda Pública. 3 ed. Belo Horizonte: Del Rey. 2019.

GAIO JÚNIOR, Antônio Pereira; PINHO, Humberto Dalla Bernardina (Coords.). Teoria Geral do Processo Civil. Novos Paradigmas frente ao CPC/2015. Rio de Janeiro: GZ, 2018.

GRINOVER, Ada Pellegrini. Ensaio sobre a processualidade. Brasília: Gazeta Jurídica, 2016.

\section{GRUPO DE PESQUISA PROCESSO CIVIL E DESENVOLVIMENTO (UFRRJ/CNPq).}

O Processo em sua perspectiva externa: meio de promoção do desenvolvimento como qualidade de vida - por uma nova fase metodológica do Processo. In: GAIO JÚNIOR, Antônio Pereira. Direito Processual em Movimento. Vol. VIII. Curitiba: CRV, 2019, p.117-154.

\footnotetext{
${ }^{36}$ Disponível em: <https://www.ecommercebrasil.com.br/noticias/e-commerce-cresce-abril-faturacompreconfie-coronavirus/> . Acesso em 26.06.2020.

37 “(...) online court activity is undertaken asynchronously, which means there is no need for everyone to be available at the same time. Like using email, participants can make their contrinutions whenever suits them. Diaries do not need to be aligned. And judges do not need to be sitting at their laptops when parties submit their documents. "SUSSKIND, Richard. Online Courts and The Future of Justice. Oxford: Oxford University Press, 2019, p.143.
} 
JAPIASSÚ, Hilton; MARCONDES, Danilo. Dicionário básico de Filosofia. 3 ed. Rio de Janeiro: Jorge Zahar Editor, 1996.

NÓBREGA, Maílson da. Brasil: um novo horizonte. In: ZYLBERSZTAJN, Décio; SZTAJN, Rachel. (Orgs.) Direito e Economia. Análise Econômica do Direito e das Organizações. Rio de Janeiro: Elsevier, 2005, p. 284-309.

NUSDEO, Fábio. Curso de Economia: Introdução ao Direito Econômico. 5 ed.. São Paulo: RT, 2008.

PINHEIRO, Armando Castelar. Magistrados, Judiciário e Economia no Brasil. In: ZYLBERSZTAJN, Décio; SZTAJN, Rachel. (Orgs.) Direito e Economia. Análise Econômica do Direito e das Organizações. Rio de Janeiro: Elsevier, 2005, p. 244-283. SALAZAR, Alcino. Poder Judiciário. Bases para Reorganização. Forense: Rio-São Paulo, 1975.

SEN, Amartya. Development as freedom. New York: Anchor Books, 2000.

SUPREMO TRIBUNAL FEDERAL. Reforma do Poder Judiciário. Diagnóstico. Brasília: Departamento de Imprensa Nacional, 1975.

SUSSKIND, Richard. Online Courts and The Future of Justice. Oxford: Oxford University Press, 2019.

VASCONCELOS, Marco Antonio; GARCIA, Manuel Enriquez. Fundamentos de economia. São Paulo: Saraiva, 1998.

\section{Documentos Eletrônicos}

https://agenciabrasil.ebc.com.br/economia/noticia/2020-04/um-em-cada-quatrobrasileileiros-nao-tem-acesso-internet . https://www.amb.com.br/coronavirus-confira-decisoes-do-judiciario-relacionadas-aoenfrentamento-da-pandemia/?doing_wp_cron=1589496577.2177391052246093750000. https://www.arcgis.com/apps/opsdashboard/index.html\#/bda7594740fd4029942346 $7 b 48$ e9ecf6. https://www.cnj.jus.br/wpcontent/uploads/conteudo/arquivo/2019/08/justica/contten/uploa ds/conteudo/arquivo/2019/08/justica_em_numeros20190919.pdf . https://coronavirus.saude.gov.br/sobre-a-doenca\#o-que-e-covid . 
https://www.ecommercebrasil.com.br/noticias/e-commerce-cresce-abril-faturacompreconfie-coronavirus/ .

https://exame.abril.com.br/ciencia/desenvolver-vacina-para-covid-19-em-dois-anos-seriaum-recorde-di z-kalil/.

https://www.ft.com/content/19d90308-6858-11ea-a3c9-1fe6fedcca75 .

https://g1.globo.com/sp/sao-paulo/noticia/2020/03/17/estado-de-sp-tem-o-primeiro-ca so-de-morte-provocada-pelo-coronavirus.ghtml .

https://g1.globo.com/sp/sao-paulo/noticia/2020/02/25/ministerio-da-saude-investiga-p ossivel-paciente-com-coronavirus-em-sp-caso-foi-para-contraprova.ghtml .

https://noticias.uol.com.br/saude/ultimas-noticias/redacao/2020/03/19/primeira-vitima -do-rj-era-domestica-e-pegou-coronavirus-da-patroa.htm .

http://portal.stf.jus.br/noticias/verNoticiaDetalhe.asp?idConteudo=440825\&ori=1 . https://www.google.com/search?q=covid+brasuil\&oq=covid+brasuil\&aqs=chrome..69i57j 017.5159j0j4\&sourceid $=$ chrome $\&$ ie $=U T F-8$.

https://www.pordata.pt/Europa/Magistrados+Judiciais+por+100+mil+habitantes-3355 . https://www.saude.gov.br/noticias/agencia-saude/46493-coronavirus-com-8-casos-co nfirmados-brasil-monitora-636-suspeitos . http://www.stj.jus.br/sites/portalp/Paginas/Comunicacao/Noticias/Ministra-extingue-p rocesso-de-paciente-com-suspeita-de-coronavirus-que-exigia-tratamento-comcloroquina.aspx .

http://www.stj.jus.br/sites/portalp/Paginas/Comunicacao/Noticias/Pandemia-nao-dispe nsa-analise-da-situacao-individual--diz-ministro-ao-negar-prisao-domiciliar-coletiva-noAM.aspx .

ttp://www.stj.jus.br/sites/portalp/Paginas/Comunicacao/Noticias/Ministro-libera-valor es-de-penhora-fiscal-para-que-empresa-pague-salarios-durante-pandemia.aspx . http://www.stj.jus.br/sites/portalp/Paginas/Comunicacao/Noticias/Em-meio-a-pandem ia--ministro-determina-que-bebe-saia-de-abrigo-e-fique-com-casal-interessado-naadocao.aspx . https://www.who.int/emergencies/diseases/novel-coronavirus-2019 . 